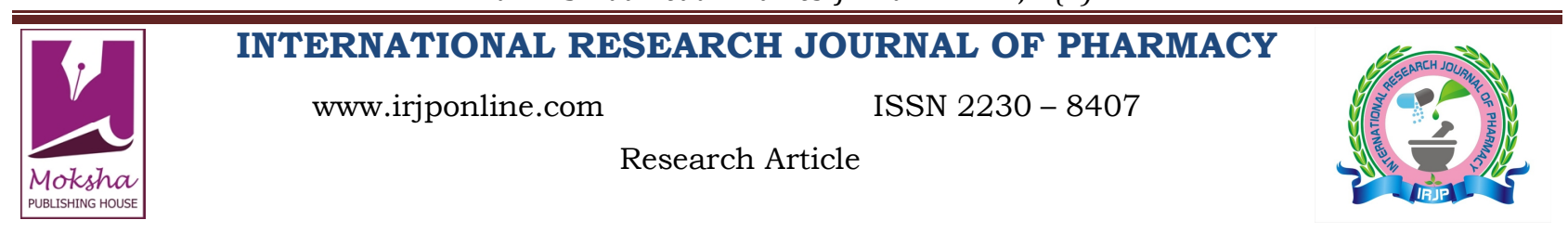

\title{
ROLE OF COPPER AND IRON DEFICIENCIES IN PATHOGENESIS OF RECURRENT APHTHOUS ULCER Laxmi Shruthi $^{1 *}$, Shetty Pushparaja ${ }^{1}$, Pandey Bhavna ${ }^{2}$ \\ ${ }^{1}$ Department of Oral Pathology \& Microbiology, A.B. Shetty Memorial Institute of Dental Sciences, Mangalore, Karnataka, India \\ ${ }^{2}$ Department of Oral Pathology \& Microbiology, Vydehi Institute of Dental Sciences, Bangalore, Karnataka, India \\ *Corresponding Author Email: laxmigbhat@gmail.com
}

Article Received on: 20/03/13 Revised on: 11/04/13 Approved for publication: 11/05/13

DOI: 10.7897/2230-8407.04546

IRJP is an official publication of Moksha Publishing House. Website: www.mokshaph.com

(C) All rights reserved.

\section{ABSTRACT}

The aim of the study was to estimate the serum levels of copper and iron in recurrent aphthous ulcer (RAU) patients and to compare these levels with normal healthy individuals. A total of 60 patients were examined with 30 recurrent aphthous ulcer (RAU) patients and 30 healthy controls. Serum samples obtained from the patients were digested using nitric acid and subjected to atomic absorption spectrophotometer for copper estimation. Serum iron was estimated using Bathophenanthroline method. All parameters were statistically analysed using student's t- test. A highly significant decrease in serum levels of copper and iron were seen in recurrent aphthous ulcer patients than in healthy control group. Copper and iron deficiencies may play a key role in etio-pathogenesis of recurrent aphthous ulcer.

Keywords: Recurrent aphthous ulcer, copper, iron.

\section{INTRODUCTION}

Recurrent aphthous stomatitis (RAS) is recognized as the most common oral mucosal disease. Epidemiologic studies indicate that prevalence of recurrent aphthous stomatitis is between $25 \%-30 \%$ in general population. Recurrence is the hallmark of recurrent aphthous ulcer and three month recurrence rates are as high as $50 \%{ }^{1}$. RAS is characterised by recurrent, small, round, or ovoid ulcers often multiple with circumscribed margins, erythematous haloes, and yellow or grey floors that present first in childhood or adolescence ${ }^{2}$. Stanley has classified RAU into three variants namely minor aphthous ulcer, major aphthous ulcer and herpetiform ulcer ${ }^{3,4}$. Local, systemic conditions, genetic, immunologic, and infectious microbial factors have been proposed as contributory factors in $\mathrm{RAU}^{5}$. Nutrition as a major contributing factor in recurrent aphthous ulcer is debatable. Haematinic deficiency is found in up to $20 \%$ of patients ${ }^{1}$. Supplementation of aphthous ulcer with zinc and copper sulphate has known to cause fast recovery ${ }^{6}$. Thus numerous attempts have been made to prove the role of nutrition in aetiology and management of RAU. However no conclusive results are available on the role of copper and iron in aetiology and management of RAU, especially in Indian population. Hence this study was planned to assess the role of copper and iron in etio-pathogenesis of RAU.

\section{MATERIALS AND METHODS}

A total of 60 patients in the age range of 20 to 40 years were examined with 30 recurrent aphthous ulcer patients and 30 healthy controls from Out Patient Department of a private dental college in Mangalore. The study group consisted of patients diagnosed with recurrent aphthous ulcer. Diagnosis of recurrent aphthous ulcer was made in the Out Patient Department by a single examiner in order to avoid any interexaminer variability. Inclusion criteria included those patients who have experienced at least 3 recurrences of aphthous ulcer in past one year and were examined between third and fifth day of ulcer period. The control group consisted of healthy individuals with clinically normal oral mucosa who reported to the dental hospital for routine diagnostic and therapeutic purposes. Exclusion criteria of the study included patients with systemic diseases, traumatic ulcers, ulcers due to hormonal changes, ulcers as a part of ulcerative colitis, Chron's disease, Behcet's syndrome, and Reiter's syndrome, ulcers related to food allergies, drug induced ulcers and those on copper and/or iron supplementations. Ethical clearance was obtained from an institutional review board to carry out the study and written informed consent was obtained from the patients. Performa inventory was completed detailing name, age, gender, and relevant medical history. Clinical history related to site, frequency, number, and type of recurrent aphthous ulcer was recorded. Preliminary blood investigations were carried out for RBC count, total leukocyte count, hemoglobin, hematocrit and red blood cell indices in both control group and recurrent aphthous ulcer patients. Both the groups in the study were subjected for copper and iron analysis. Approximately $5.0 \mathrm{ml}$ of blood was drawn from the patients by venipuncture using a sterile disposable syringe. Blood samples were subjected to centrifugation at 3,000rpm for 10minutes and serum was separated. These samples were stored at $-20^{\circ} \mathrm{c}$ until shortly before assay.

Ethical Clearance Number: Absm/Ec/80/2010 on 22/10/10

\section{Copper Estimation}

Serum samples were digested using nitric acid and serum copper concentration was determined using atomic absorption spectrophotometer. About $20 \mu \mathrm{l}$ of each sample was introduced through sample port into the Nebulizer, where sample gets converted into tiny aerosols. These aerosols were fed into the air-acetylene flame where the atomization of the sample occurs and copper present gets excited. These excited copper atoms absorb energy from the spectrum produced by the copper hallow cathode lamp. The decrease in energy is measured which is directly proportional to the concentration of the copper atoms. Absorbance signal was measured and the concentration of copper in each sample was determined by comparison of its absorbance signal with that of the standard solutions with known copper concentrations. 


\section{Iron Estimation}

Serum iron was estimated using Bathophenanthroline method. An average of $100 \mu \mathrm{l}$ of serum sample was taken in a clean microfuge tube and made up to $250 \mu$ l with deionised water. To this diluted sample, $500 \mu \mathrm{l}$ of protein precipitating solution was added. The mixture is then centrifuged at $2000 \mathrm{rpm}$ for 10 minutes. An average of $500 \mu \mathrm{l}$ of supernatant was taken and added to $500 \mu \mathrm{L}$ of the chromogen solution.
The optical density of the pink colour formed was read immediately at $535 \mathrm{~nm}$ against a blank treated in a similar method as the test where in the sample was replaced with the deionised water. Comparison between means of study and control groups was done using student's t-test in SPSS software version 13.0. Probability values, $\mathrm{p}<0.05$ were considered as significant ( $\mathrm{s}$ ) and $\mathrm{p}<0.01$ were considered as highly significant (HS).

Table 1: Comparison of Mean Serum Copper Levels in Study and Control Groups

\begin{tabular}{|c|c|c|c|c|c|c|c|c|}
\hline Group & $\mathbf{N}$ & Minimum & Maximum & Mean & Std. Deviation & Median & t value & p value \\
\hline Study group & 30 & 70.00 & 84.00 & 75.95 & 4.55 & 75.00 & 12.785 & .000 \\
\hline Control group & 30 & 86.00 & 113.00 & 93.90 & 6.19 & 93.00 & & HS* \\
\hline Total & 60 & 70.00 & 113.00 & 84.93 & 10.53 & 85.00 & & \\
\hline
\end{tabular}

*Highly significant at $1 \%$ level of significance $(\mathrm{p}<0.01)$

Table 2: Comparison of Mean Serum Iron Levels in Study and Control Groups

\begin{tabular}{|c|c|c|c|c|c|c|c|c|}
\hline Group & $\mathbf{N}$ & Minimum & Maximum & Mean & Std. Deviation & Median & t value & p value \\
\hline Study group & 30 & 8.83 & 9.57 & 9.25 & .15 & 9.27 & 9.391 & .000 \\
\hline Control group & 30 & 9.40 & 10.32 & 9.78 & .27 & 9.72 & & HS* \\
\hline Total & 60 & 8.83 & 10.32 & 9.52 & .35 & 9.42 & & \\
\hline
\end{tabular}

*Highly significant at $1 \%$ level of significance $(\mathrm{p}<0.01)$

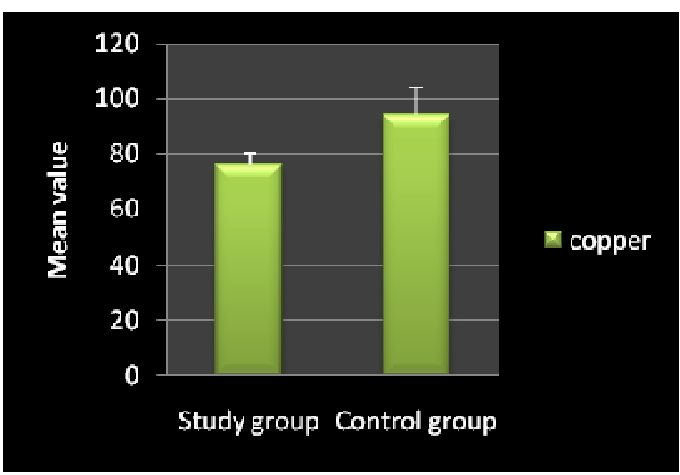

Figure 1: Comparison between mean serum copper levels of study group and control group

\section{RESULTS}

The age of patients in control and study group ranged between 20 and 40 years. In the present study all the 30 recurrent aphthous ulcer patients showed minor type of recurrent aphthous ulcer. Among recurrent aphthous ulcer (RAU) patients, $60 \%$ were females and $40 \%$ male. Among control group $60 \%$ were males and $40 \%$ females. Most common site of RAU was labial mucosa $(46 \%)$ followed by buccal mucosa $(27 \%)$, tongue $(17 \%)$, and floor of the mouth $(10 \%)$. Most patients gave the history of frequency of occurrence of RAU to be once in three months (50\%). There was statistically highly significant decrease in serum levels of copper (Table 1, Figure 1) as well as iron in recurrent aphthous ulcer patients when compared to control group (Table 2, Figure 2).

\section{DISCUSSION}

Recurrent aphthous stomatitis (RAS) is a disease characterized by appearance of small round to oval recurring ulcers in the oral mucosa without any sign of other diseases. Episodes of recurrent aphthous ulcers may be infrequent resulting in mild or only transient symptoms or may be continuous causing persistent pain and disability over extended period of time. RAS occurs in men and women of all ages, races and geographic regions. The peak age of onset of RAS is the second decade of life ${ }^{7}$. Attacks of recurrent aphthous ulcer may be precipitated by local trauma, stress,

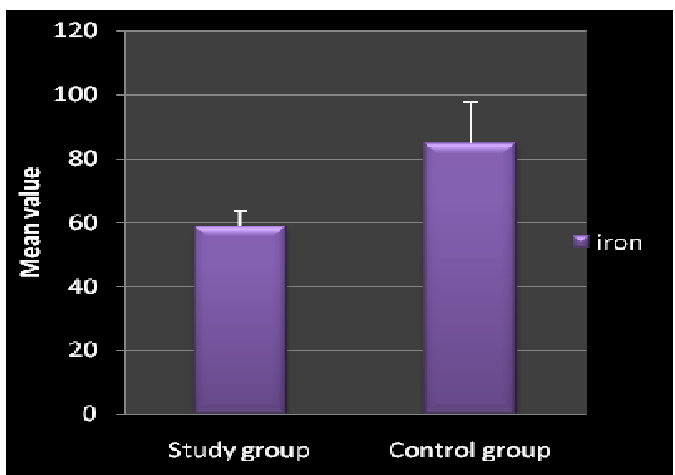

Figure 2: Comparison between mean serum iron levels of study group and control

food intake, drugs, hormonal changes, vitamin and trace element deficiencies ${ }^{4}$. Recently more emphasis is being laid on micronutrient deficiencies in recurrent aphthous ulcer patients. Adequate intakes of micronutrients like copper, iron, and zinc are required for the immune system to function efficiently. Micronutrients contribute to the body's natural defences on three levels by supporting physical barriersskin/mucosa, cellular immunity and antibody production. Micronutrient deficiency suppresses immunity by affecting innate, $\mathrm{T}$ cell mediated and adaptive antibody responses, leading to dysregulation of the balanced host response ${ }^{8}$. Micronutrients in the body have known to show interactions. Copper and iron levels are interdependent as iron requires copper dependent enzymes. The best-characterised link between copper and iron is provided by ceruloplasmin, a multi-copper binding protein that acts as a serum ferrioxidase and is essential for the mobilisation of iron from storage tissues. Decreased copper status is known to reduce ceruloplasmin production and impair ferrioxidase activity thus leading to decreased tissue iron release resulting in iron deficiency anaemia. Dietary iron absorption also requires the presence of a multi-copper ferrioxidase ${ }^{9}$. Treatment of recurrent aphthous ulcer patients with copper sulphate is known to reduce the severity and incidence of ulcers. In the present study serum copper were significantly lower in recurrent aphthous patients than in healthy control group. These findings are in accordance to study conducted by Bor 
$\mathrm{N} \mathrm{M}$ et al. in $1990^{6}$ where copper sulphate treatment of 67 patients revealed complete recovery of ulceration in 40 patients and 22 showed definite improvement after 3 months of treatment. But according to the study conducted by Pang $\mathrm{JF}$ in $1992^{10}$ copper levels were within the normal range in recurrent aphthous ulcer patients. Iron is essential regulation of cell differentiation and cell growth ${ }^{8}$. Cytochrome oxidase is an iron-dependent enzyme which is required for the normal maturation of the epithelium. In iron deficiency state, the levels of cytochrome oxidase are low, consequently leading to epithelial atrophy. An atrophic epithelium makes the oral mucosa vulnerable to the soluble irritants. Lack of iron in tissues causes improper vascular channel formation resulting in decreased vascularity. This leads to derangement in the inflammatory- reparative response of the lamina propria resulting in defective healing ${ }^{11}$. Iron deficiency is known to cause recurrent aphthous ulcer. Relationship of recurrent aphthous ulcer to iron deficiency which in itself may be associated an underlying gastrointestinal disorder or a poor diet. In the present study serum iron level was determined by Bathophenanthroline method. Present study shows that serum iron levels are significantly lower in recurrent aphthous ulcer patients compared to normal healthy controls which is in accordance to studies conducted by Wray D et al. in $1978^{12}$, Hutcheon A W in $1978^{13}$, Porter S R et al. $1988^{14}$, Barnadas MA et al. in $1997^{15}$, Burgan SZ et al. in $2006^{16}$ and Ogura M et al. in $1998^{17}$. But according to studies conducted by Koybasi S et al. in $2006^{7}$, Olson A et al. in $1982^{18}$, and Piskin $\mathrm{S}$ et al. in $2002^{19}$ iron deficiency was not found in recurrent aphthous ulcer patients. There was no significant difference between iron levels in study and control groups. Also according to studies conducted by Wray D et al. in $1975^{20}$ and Challacombe SJ et al. in $1975^{21}$ replacement therapy with iron for recurrent aphthous ulcer patients has shown less or no response. This inconsistent response to iron replacement therapy was because patients in study group had low serum iron levels secondary to chronic disease and not due to primary iron deficiency anaemia.

\section{CONCLUSION}

Recurrent aphthous ulcer is a multi-factorial disease. Present study suggests that combined nutritional deficiencies, especially copper and iron can occur in recurrent aphthous ulcer. Hence routine haematological investigations of copper and iron may be carried out in recurrent aphthous ulcer patients. Also supplementations of copper and iron in recurrent aphthous ulcer patients may prevent or decrease the frequency of recurrent aphthous ulcers.

\section{REFERENCES}

1. Barrons RW. Treatment strategies for recurrent oral aphthous ulcers. Am J Health Syst Pharm. 2001; 58: 41-50. PMid:11194135

2. Jurge S, Kuffer R, Scully C, Porter SR. Mucosal Disease Series, Number VI Recurrent aphthous stomatitis, Oral dis. 2006; 12: 1-21. http:// dx.doi.org/10.1111/j.1601-0825.2005.01143.x PMid: 16390463

3. Stanley HR. Aphthous lesions. Oral Surg Oral Med Oral Pathol Oral Radiol Endod. 1972; 33(3): 407-416.
4. Natah SS, Konttinen YT, Enattah NS, Ashammakhi N, Sharkey KA, Hayrinen-Immonen R. Recurrent aphthous ulcers today: a review of the growing knowledge. Int.J. Oral Maxillofac. Surg.2004; 33: 221-234. http://dx.doi.org/10.1006/ijom.2002.0446 PMid:15287304

5. Ship JA, Chavez EM, Doerr PA, Henson BS, Sarmadi M. Recurrent aphthous stomatitis. Quintessence Int.2000; 31: 95-112. PMid:11203919

6. Bor NM, Karabiyikoglu A, Karabiyikoglu T. Treatment of Recurrent Aphthous Stomatitis with Systemic Zinc Sulphate. JIA Sci.1990; 3: 34347.

7. Koybasi S, Parlak A H, Serin E, Yilmaz F, Serin D. Recurrent Aphthous Stomatitis: investigation of possible etiologic factors. Am J Otolaryngol. $2006 \quad$ Jul-Aug; 27(4): 229-232. http://dx.doi.org /10.1016/j.amjoto.2005.09.022 PMid:16798397

8. Maggini S, Wintergerst ES, Beveridge S and Hornig DH. Selected vitamins and trace elements support immune function by strengthening epithelial barriers and cellular and humoral immune responses. British Journal of Nutrition. 2007; 98 (Suppl. 1): S29-S35. http://dx.doi.org/ 10.1017/S0007114507832971 PMid: 17922955

9. Sharp P. The molecular basis of copper and iron interactions. Proc Nutr Soc. 2004 Nov; 63(4): 563-9. http://dx.doi.org/10.1079/PNS2004386 PMid: 15831128

10. Pang JF. Relation between treatment with traditional Chinese medicine for recurrent aphthous ulcer and human zinc and copper. Zhongguo Zhong Xi Yi Jie He Za Zhi. 1992 May; 12(5): 280-2, 260-1.

11. Karthik H, Nair P, Gharote HP, Agarwal K, Bhat GR and Rajaram DK. Role of Hemoglobin and Serum Iron in Oral Submucous Fibrosis: A Clinical Study. The ScientificWorldJournal, 2012; 2012: 254013. Epub 2012 Apr 30.

12. Wray D, Ferguson MM, Hutcheon WA, Dagg JH. Nutritional deficiencies in recurrent aphthae. J Oral Pathol 1978; 7(6): 418-23. http://dx.doi.org/10.1111/j.1600-0714.1978.tb01612.x PMid:105102

13. Hutcheon AW, Wray D, Ferguson MM, Dagg JH \& Mason DK. Clinical and Hematological Screening in recurrent aphthae. Postgrad Med J. December 1978; 54(638): 779-783. http://dx.doi.org/10.1136/ pgmj.54.638.779 PMCid:2425364

14. Porter SR, Scully C, Flint S. Hematologic status in recurrent aphthous stomatitis compared with other oral disease. Oral Surg Oral Med Oral Pathol 1988; 66(1): 41-4. http://dx.doi.org/10.1016/00304220(88)90064-3

15. Barnadas MA, Remacha A, Condomines J, de Moragas JM. Hematologic deficiencies in patients with recurrent oral aphthae. Med Clin (Barc). 1997 Jun 14; 109(3): 85-7.

16. Burgan SZ, Sawair FA, Amarin ZO. Hematologic status in patients with recurrent aphthous stomatitis in Jordan. Saudi Med J 2006 Mar; 27(3): 381-4. PMid:16532102

17. Ogura M, Yamamoto T, Morita M, Watanabe T. A case control study on food intake of patients with recurrent aphthous stomatitis. Oral Surg Oral Med Oral Pathol Oral Radiol Endod. 2001 Jan; 91(1): 45-9. http://dx.doi.org/10.1067/moe.2001.110414 PMid:11174570

18. Olson A, Feinberg I, Silverman S, Abrams D, Greenspan JS. Serum vitamin $\mathrm{B}_{12}$, folate and iron levels in recurrent aphthous ulceration. Oral Surg Oral Med Oral Pathol. 1982 Nov; 54(5): 517-20. http:// dx.doi.org/10.1016/0030-4220(82)90189-X

19. Piskin S, Sayan C, Durukan N, Senol M. Serum iron, ferritin, folic acid, and vitamin B12 levels in recurrent aphthous stomatitis. J Eur Acad Dermatol Venereol. 2002 Jan; 16(1): 66-7. http://dx.doi.org/ 10.1046/j.1468-3083.2002.00369.x PMid:11952294

20. Wray D, Ferguson MM, Mason DK, Hutcheon AW, Dagg JH. Recurrent aphthae: treatment with vitamin B12, folic acid, and iron. Br Med J. 1975 May 31; 2(5969):490-3. http://dx.doi.org/10.1136/bmj.2.5969.490 PMid:1148667 PMCid:1673414

21. Challacombe SJ, Barkhan P, Lehner T. Haematological features and differentiation of recurrent oral ulceration. Br Med J. 1975 Jul; 15(1): $37-48$.

\section{Cite this article as:}

Laxmi Shruthi, Shetty Pushparaja, Pandey Bhavna. Role of copper and iron deficiencies in pathogenesis of recurrent aphthous ulcer. Int. Res. J. Pharm. 2013; 4(5):219-221 